\title{
Coping with Parental Mental Illness - An Everyday Battle
}

\author{
Vedavati Paranjape \\ Assistant Professor, Department of Psychology, Joshi-Bedekar College, Thane.
}

Corresponding author: Vedavati Paranjape

Email-veda18985@gmail.com

\begin{abstract}
Mental illness is referred to as a condition that tends to impact a person's thinking, feeling or mood and may affect his or her ability to relate to others and function on a daily basis. Many children may grow up with a parent suffering from some mental health condition at some point of time in his/her life. Few of these children live with a parent who has severe psychiatric illness such as schizophrenia or bipolar disorder. Coping with the stress of parental psychiatric illness is often very challenging for children as such illness creates an inconsistent, unpredictable family environment and may seriously hamper the parenting abilities of the couple. Children of such parents, while battling every day with the disorder of their parent, often experience stress of caring for the ill parent and also responsibility of siblings. They may themselves experience an array of problems including difficulties in concentrating on studies, anxiety, fear of developing same illness, so on and so forth. However, despite of these difficulties, some of these children seem to be achieving extraordinary success in their lives. They not only are able to do well in academics, but also maintain their emotional health, develop and sustain good relationships and at times reach out to help other individuals suffering from similar conditions out of compassion. What factors could be underlying this healthy coping? Could it be accounted to the differences in personality, resilience or specific coping strategies used by them? The present paper is a humble attempt to find answers to these questions. The aim of the study is to develop an in-depth understanding of above mentioned and many other such factors. Hence the qualitative analysis has been used. Specific research method used is narrative analysis which includes interviews with some such children (adult children). The implications of the research can be found in individual as well as group counseling, schools, colleges and other mental health care facilities.
\end{abstract}

Key Words: coping, children, parental, parents, mental illness

(Paper received $-27^{\text {th }}$ November 2017, Peer review completed $-12^{\text {th }}$ December 2017 )

(Accepted - 20 ${ }^{\text {th }}$ December 2017)

\section{INTRODUCTION}

Stress is simply a reaction to a stimulus that disturbs our physical or mental equilibrium. In other words, it's an omnipresent part of life. Stress is categorized in to two types: acute stress and chronic stress. Acute stress is the most common type of stress. It's body's immediate reaction to a new challenge, event, or demand, and it triggers fight-or-flight response [1]. If acute stress isn't resolved and begins to increase or lasts for long periods of time, it becomes chronic stress. This stress is constant and doesn't go away. It can stem from such things as poverty, a dysfunctional family, an unhappy marriage or a bad job. Chronic stress can be detrimental to health, as it can contribute to several serious diseases or health risks, including heart disease, cancer, lung disease, accidents, etc [2].

Stress could be attributed to several sources. They are generally categorized as External and Internal factors. External factors include things like major life changing events, environment, unpredictable 
happenings, tensions at workplace whereas internal factors include personality, beliefs, attitudes, etc. one of the major external factor is family. While being typically recognized as support system and source of strength, certain pressures in familial life of an individual can definitely contribute to the stress. Such factors include difficulty in managing money, chronic illness of spouse, abuse/harassment by some family member, inability to give time to each other, etc. Despite of the categorization, most of the times external and internal factors tend to interact with each other, deciding the intensity of the experience of stress felt by the individual [3].

From the point of view of current study the pressures present at family which act as a source of stress are of chief importance. Also the interaction between this external force and some internal factors is of immense value. In his article 'The family as a source of stress' Croog [4] opines that while the role of family is considered as important in coping with stress and many interventions have been developed to include the family in an individual's effort to reduce stress, there is comparatively very less systematic attention is given to the family as a source of stress. According to Croog, the problem has received some attention in creative art and literature. Depictions of man suffering because of family have been constructed in history through various masterpieces like Oedipus, Anna Karenina, Romeo and Juliet, etc. there is substantial body of research which traces various negative consequences like delinquency, mental illness, immorality back to the family. These researches have made significant contribution in development of certain theoretical approaches and interventions. Yet, there is little understanding of the role of the entire family as a source of stress as compared to considering only certain aspects of family which might be responsible for the experience of stress [5].

While working as a Psychology professor as well as counselor I have come across some such youngsters whose one of the parent is suffering from some psychiatric illness. I have had the fortune of witnessing their frustrations, struggles and also the growth resulting from their everyday battles with illness. There were some questions which haunted me, like for example, which emotions these children must be experiencing constantly? How do they shoulder the responsibility of caring for a disturbed parent? How much support do they get from society? Knowingly or unknowingly do they use any specific coping strategies? Answers to these and many such questions may have larger implications in helping people device some healthy coping strategies to deal with such situations in the family. With these aims in mind I have embarked on choosing this topic for research.

A fact which invokes some academic curiosity is that many studies on effects of parental mental illness on children focus on mother's illness. Masten [6] found in his study that children with a schizophrenic parent may not obtain comforting caregiving compared to children with healthy parents, and such situations had an impact on children's development. However, some children of ill parents thrived well and were competent in academic achievement, and therefore led researchers to make efforts to understand such responses to adversity.

In a study on psychosocial outcomes for adult children of parents with several mental illness Mowbray and others [7] have used a sample of 379 mothers with serious mental illnesses, 157 women who had at least one adult child between the ages of 18 and 30 were interviewed. Mothers reported that about 80 percent of these adult children were working, in school, or in training. However, about one-third had not completed high school, and 54 percent were judged to have a major problem in psychological, drug or alcohol or legal domains. Although nearly 40 percent were parents of minor children, only about 12 percent were in a committed relationship. Mothers' bipolar diagnosis was a significant predictor for number of adult child problems. The results indicate a need for more attention to the parenting status of adults with mental illnesses and to their parenting concerns and needs [8].

In another comprehensive review of literature, Oyserman, Mowbray, Meares and Firminger [9] found that, in comparison to parents without a diagnosis of mental illness, parents with mental illness were less responsive to their infants, less emotionally available and less involved with their pre-schoolers, and less encouraging with their school aged children. In addition parents with mental illness, in comparison to parents without a diagnosis of mental illness, were found to be inconsistent, less happy, less talkative with their children, more critical with their children and found to have an inability to sustain social interaction (Oyserman et al., 2000). 
In a research on family structure and physical punishment it was found by Nobes and Smith [10] that among mothers with poor mental health, those with partners reported having used more severe physical punishments.

While most research focuses on how parental mental illness affects children adversely, a study done by Diaz-Caneja and Johnson [11] tries to understand the views and experiences of severely mentally ill mothers. They have carried out Semi-structured interviews with 22 women with schizophrenia, bipolar affective disorder or severe depression with psychotic symptoms in Inner London. Participants' experiences, views about services and needs for support in parenting were discussed. Most participants in their study described motherhood as rewarding and central to their lives. However, they described the demands associated with parenting and at the same time coping with severe mental illness as considerable, and some feared that their children would be adversely affected by their illnesses. Parenting responsibilities created practical impediments to engaging with mental health services. Fear of losing custody or access to children dominated interactions with mental health and social services, making most participants reluctant to disclose difficulties in parenting to professionals. A widespread assumption that mentally ill women are inherently poor parents, regardless of the facts of individual cases, was also described, and stigma was seen as affecting children as well as mothers. Services were perceived by participants as offering little continuing support in relation to parenting, intervening only in crises.

The present research aims to find out how children interpret and deal with the familial reality of mental illness. To be able to achieve this qualitative research has been undertaken.

\section{METHODOLOGY}

The study is qualitative in nature. Specific methods used are interviews and narrative analysis. In-depth interviews of 2 adult children have been taken. The data generated from these have been analyzed to see if any common thread is found in terms of efforts made to cope with the situation.

Both of these adult children have taken help from the counseling cell of our college. Their mothers have been suffering from different mental illnesses. Both of them have been witnessing as well as fighting battle with these illnesses almost from 20 years.

The in-depth interview with them was done in 2 sessions of an hour each. Narration is based on the data generated from these interviews. Since both the parents were not in formal, systematic treatment, no evidence like prescriptions of doctor or diagnosis can be obtained. Not limiting the whole effort to merely gather information from the participants, I aim to continue helping them through counseling, at times even working in capacity of mentor.

\section{Method of Narrative Analysis}

As mentioned by Susan Chase in her article 'Narrative Inquiry: Multiple Lenses, Approaches, Voices; narrative is considered as retrospective meaning making- the shaping or ordering of past events. However, it is different from mere chronology as it communicates narrator's point of view, including why the narrative is worth telling in the first place. Thus, in addition to describing what happened, narratives also express emotions, thoughts and interpretations [12].

While interpreting narratives heard during interviews, a researcher would often listen to the voices within each narrative and then try to see the common themes that may emerge across the narratives. A researcher looks for patterns, themes, regularities as well as contrasts, paradoxes and irregularities. Several research paradigms are used to interpret the data gathered. In this research constructivist paradigm has been used. Consistent with the approach, present research relies upon participants' views of the situation. It has aim of understanding the human experience of coping with difficult circumstances at home. The research did not begin with a theory but rather has tried to generate/develop a pattern of meanings throughout the research process. 


\section{CASE DESCRIPTIONS}

(Names of both the participants have been changed to maintain confidentiality.)

\section{Case 1}

Meera is 21 years old college going girl. Currently, she is studying in T.Y.B.A. with Psychology as her major subject. Residing at Thane, Meera belongs to a typical Maharashtrian family. She, her mother and father are only family members, as she is an only child. Her father works as pathologist in a company and mother does freelancing for handling PR of some community projects. Meera's mother is suffering from depression.

In the year 2014, due to some health issue, they had to take the mother to a multispecialty well known hospital in the city. After talking to her, the doctor has felt the need for psychiatric treatment along with other medicines. Keeping in line with his suggestion, 3 sessions with a counselor have happened. However, later when the counselor went out of the city for some duration, meera's mother has lost interest in continuing the therapy. The medicines prescribed by psychiatrist were also discontinued by her after a week due to unpleasant side effects.

Although, this brief treatment was sought only before 2 years, the depression suffered by Meera's mother is a story dated very long back than that. There was a period when she was young, when she would not talk with anyone, would not go out, would not even move from her place for days, but would just sit in her cocoon and cry/remain upset. Symptoms which probably have subsided for some time became aggravated with troubled marriage and especially with one incidence where she was verbally abused by her alcoholic father-in-law. Reaction of Meera's father felt too subtle to her mother. She interpreted it as lack of support, sensitivity and protection which a husband should provide to his wife and could never forgive him for this. After this incidence everything at home changed and it kept getting worse. Meera was approximately 8 years old at the time of this incidence. She was very close to her mom since beginning and always witnessed the episodes of emotional upheaval of her mom. Among others, such episodes mainly consisted of crying spells, agitation, anger, giving up control on the body, not opening eyes, etc. Since her childhood, Meera has tried to be there during such times and provide whatever care she could to mom. Her mother has often expressed her feelings, frustrations, sadness and anger to Meera. Apart from such episodes, the mother is agitated, upset or angry most of the times. Smallest details, household trouble make her extremely angry. Sometimes, the anger turns to Meera also, deeming her as worthless daughter who has not been caring enough for her mother or doing any great things in her life. Failing to control herself, many a times Meera also reacts with anger. In $7^{\text {th }}$ std Meera was referred to school counselor for anger management.

While caring immensely for the physical illness of his wife, Meera's father is not able to show same care towards her psychological issues. When she starts crying or is angry, agitated, he prefers to retire to other room. In the beginning he would call her brother to come to pacify her. However, he would end blaming and cursing her for being unable to maintain ideal conduct at her in-law's place. Now, without any other person to be there, the entire responsibility of caring for mother and being there for her is upon Meera. While trying to fulfill it, she feels immensely sad about expressed feelings of her mother, especially about death. Suffering from many physical maladies, her mother strongly feels that she would not be able to live for more than 5-6 years, which makes Meera feel very lonely and sad. As she was a witness to her mother's troubles and absence of her father, Meera could not form any great bond with her father. However, there are various restrictions imposed on her by him in terms of going out with friends, time to come home, etc. she feels tensed about these pressures and scared of him. According to her, he was never happy with her despite of all her efforts to be a good daughter.

Meera's grandmother has been extremely critical of her daughter (Meera's mother). Therefore, the support from her own family was also absent.

Constricted by various restrictions put on her as well as her own fear that people would not comprehend her situation exactly, Meera does not have many friends. She is an introvert and does not enjoy talking to people a lot. Her best friend also is suffering from clinical depression, including occasional desires to kill herself and Meera could not share much of her own troubles with her. With her boyfriend she shares some of the things, however she fears that if she keeps talking about her problems all the time then he 
would get bored and that might affect their relationship. She has a close relation with one of her cousin who knows and understands the situation of her mother and related turmoil. The talk of his marriage tends to upset Meera as she feels it will draw him away from her.

Despite of her ailment, mom has been an only support system for Meera. She tends to share most of the important things happening in her life only with mom. And the thought of she not being there troubles Meera upto a great extent, she is unable to think of her life without mom.

So far, chief coping strategy for Meera has been sitting alone after an emotionally charged episode happens and trying to restore the peace. Meera owns 4 pet cats and feeds 2 stray ones. She describes these cats as her 'social circle'. They help her reduce the stress she feels everyday at home up to an extent. A male cat is especially close to her and she even talks to him, sharing her troubles and feelings, which serve as a great relief. According to Meera, he is her real support and keeps her sane.

When greatly agitated Meera tends to draw random faces on paper, mostly of girls. That releases some of her anger at times. Meera has hobbies like singing and baking/cooking. However, so far they have not contributed much in helping her cope with her situation.

Recently, Meera has approached counseling cell in her college and began sharing her issues with the counselor. She is also trying to work out some things/strategies that emerged in her counseling sessions. They chiefly include setting up a routine and increasing focus on studies

Apart from genuine interest in studying psychology, Meera has faint hope that when she masters the subject, she would find something which will convince her mother about seeking treatment, or something with which she can help mom.

Coping strategies emerged: Pets, doodling/drawing, seeking help from mental health professional, focusing on studies

\section{Case2}

Jagdish is currently studying MBA from a reputed institute in Pune. His father is in transportation business and mother is homemaker. He has two siblings, Jagdish is eldest . for many years they have stayed in join family, but shifted to Thane before some years, thus becoming a nuclear one.

Since the time Jagdish remembers his mother is having several disturbed behavioral patterns. She tends to be overly suspicious about his father. There are frequent angry/violant outbursts. Many times it appears to be that there is no coordination between her thoughts and verbal comments. She tends to display inappropriate affect. She is currently on medication, however she herself is not aware about the real purpose of medicines, nor has she met the doctor herself. There was no formal assessment and diagnosis made. There is no therapy or counseling also.

Jagdish holds his father responsible for many problems suffered by his mother. According to him, his father's unemotional, less sensitive attitude towards her as well as marriage as a whole has triggered these problems. He feels that many simple desires of his mom are not fulfilled and there is absence of love in their marriage.

While jagdish has always been a silent witness of all the sufferings of his mother, she has never shared any of her emotions with him, nor was her illness ever discussed to him by any other family member. For many years, Jagdish has not developed any special bond with his mother. Jagdish has felt confused, angry and frustrated throughout his childhood, questioning why would his mother not behave 'normal'? Why is she not like his other friends' mothers?

While Jagdish could not comprehend situation, his family maintained a highly insensitive attitude towards the illness (arising from their own lack of understanding about illness) which resulted in ignorance and sometimes even physical abuse. Her violent behavior was reciprocated with more violence from her husband, leading to hostile quarrels. Relatives of Jagdish have labeled his mother as 'Mad' and also frequently advised his father to remarry. Jagdish remembers an incidence when he was around 7 years old; his dad has asked him whether you want another mother. There was no specific support provided even from the family of his mother.

When he was studying in his First year of college, frustrated by everyday struggle with illness and quarrels in family, Jagdish has made a minor suicide attempt. However, noticing his depressed emotional state, one of his professors has referred him to the college counseling cell next day. Sharing his troubles with 
counselor has helped Jagdish relive the tremendous emotional stress he was experiencing. Also, in an attempt to change his perception towards the situations, counselor has suggested Jagdish to develop more empathetic attitude towards his mother and also to try developing healthier and loving bond with her.

Jagdish also believes that sharing his emotions with some close friends have helped him a lot. One of his friends has suggested him to approach a counselor too. According to him, talking with siblings is of great help, as being in the same struggle; they can exactly understand his emotions.

Over the time, Jagdish has developed an understanding that thinking always about the troubled situation would not help. He has learnt to stop thinking about same things. Also as per the suggestion of counselor he has worked on his relation with his mother and now they have a very close bond. Jagdish's expression of love has been accepted by his mom with pleasure. He also has realized that how he reacts to his mother's behavior matters more. With this he has learnt to remain calm even in her angry outbursts. He also has learnt to remain happy, to enjoy life with friends. He has some hobbies which soothe him like reading, listening music, collecting tickets.

Jagdish feels that since he has experienced troublesome situations, he can understand others' troubles as well. And thus he listens patiently to his friends' problems, tries to comfort them, help them. Being with people, helping them has helped him achieve more strength to deal with his own issues.

Being a brilliant student, Jagdish feels that studies also have helped him to defocus attention from problems.

Coping strategies emerged: seeking help from professional, changing perception/thoughts, sharing with friends/siblings, cultivating good hobbies, helping others, studies, understanding the importance of his reactions and changing them, importance of loving bond.

\section{NARRATIVE ANALYSIS AND COMMENTS}

In the beginning of this section, I would like to mention that although the research has started with the aim of understanding coping strategies used by children of parents suffering from mental health problems; there are several other important themes which have emerged from the interviews of these children.

Following section analyzes the data by elaborating on some such common themes which have emerged.

\section{Psychiatric illness of mother}

As mentioned earlier, most of the past research on the subject focuses mainly on mental illness of mother. Both the participants of the study have mothers who are victims of mental illnesses. Not only this but some major cases I have witnessed as a counselor include mother's illness. The fact makes it mandatory to consider the socio-cultural set up in which these stories are happening. Several questions emerge, such as: Is the typical secondary treatment given to women partly responsible for more mental sufferings a woman endures than men? What role the typical cultural expectations from a woman play in the development of psychological disturbance? Up to which extent this observation can be explained by genetics?

\section{Cultural stereotypes}

In both the cases, the cultural stereotypes have seemed made a major contribution in two things Aggravation of symptoms and lack of social support

The common Indian cultural stereotypes seem evident in both cases. According to these stereotypes an ideal woman is one who is beautiful, nurturing, obedient and can manage her family and household effectively. Meera's mother has been looked down at her maiden place for not being 'fair skinned'. She was also been criticized often by her brothers later for not being an 'ideal' wife or married lady that every girl supposed to be. Similarly, jagdish's mother was harassed by her in-laws as well as husband for not being an ideal daughter in law, wife and mother. These stereotypes have created barriers in the way of understanding these women as an individual. The perceptions of their families remained colored with the expectations and disappointments rooted in the typical cultural background. As a result, no salient support could be generated from any family member for a long period of time. 


\section{Lack of Awareness about the Concept of Mental Health}

Statistics about the mental health in India shows some disturbing results:

- A study conducted by the National Commission on Macroeconomics and Health in 2005 reported that nearly $5 \%$ of India's population suffers from common mental disorders, such as depression and anxiety [13].

- As per the review of epidemiological studies conducted in 2000 , the prevalence of mental disorders in India was 70.5 per 1000 in rural and 73 per 1000 in urban population [14].

However despite on increasing number of population suffering from mental health issues, awareness about the concept of mental health and mental illnesses is shockingly inadequate. Because of this ignorance, victims of mental illness are often perceived as misbehaving deliberately or with some ulterior motive. This perception prevents any sort of treatment and rather becomes a factor which may increase the intensity of symptoms. This situation was evident in both the cases.

\section{Change Begins with Acceptance}

Carl Rogers say "The curious paradox is that when I accept myself just as I am, then I can change."

When one accepts the situations in which he has to live and which he cannot change, he begins to change his perspective towards them. And the moment such acceptance is developed difficulties are turned into challenges, strategies to cope with the disturbing illness on day to day basis are developed and sweet moments even through a disturbed household can be savored.

This acceptance is more evident in the case of Jagdish. With the newfound insights in counseling sessions, he began to accept his mother with her illness. As a result, he was able to provide some practical help to his mother. Not only that, he could learn to deal with it without getting depressed.

\section{Coping Strategies used by participants}

Founder of the well known therapeutic school Person Centered Therapy, Carl Rogers, has emphatically stated often that humans have capacity and desire for personal growth and change. According to him, individuals have within themselves vast resources for self understanding and for altering their self concepts, basic attitudes and self directed behavior.

One of the presupposition of a famous therapy, Neuro Linguistic Programming, also quotes that people have all the resources they need.

Consistent with these well researched views, participants of this study have consistently knowingly/unknowingly been finding and using different coping techniques to deal with their adversities. Some of them could be described as follows:

- Art Therapy: Art therapy is a rapidly developing therapeutic school in which art media, the creative process and resulting artwork are used to help client deal with various emotional/behavioral problems. Meera as well as Jagdish have made use (unconsciously) of art therapy. Jagdish reports that his hobby of collecting coins and maintaining this collection has helped him to divert his mind often from the everyday household conflicts. Whereas Meera often draws/doodles several pictures and reports that when she is stressed greatly, this hobby helps her to relieve her stress.

- Social Support: Both cases, in their own way, denote importance of having close friends in attempts to cope. Jagdish has often talked about his feelings to his some close friends and while trying to understand him they also have suggested seeking help from counselor. When Jagdish has started counseling sessions, his friend motivated him to continue with them. Jagdish also rejoices about the sharing he could do with his siblings because they have experienced exactly same situation as Jagdish they can understand the dynamics of it much better than anyone else. Finally, Jagdish's teacher has referred him to the college counselor, denoting once again importance of forming an integrated network to facilitate efforts of fostering mental health. On the other hand, Meera feels lonely because of lack of any such close friend.

- Animal Assisted Therapy: This therapy involves animals as a form of treatment. Although it is comparatively new school of thought, advocates of AAT state that animals can be useful for educational and motivational effectiveness. Biophilia hypothesis proposed by Wilson (1984) 
suggests that human-animal attachment seem to stem from the fact that human survival was partly dependent on signals from animals in the environment indicating safety or threat. Seeing animals at rest or in peaceful state may signal may signal to us safety, security and feelings of well being which in turn may trigger a state where personal change and healing are possible.

In case of Meera, her pet cat seems to be a great source of support and peace to her. She shares her problems with it and feels some healing taking place.

- Activity Scheduling: Activity scheduling has been an important technique used in behavioral as well as cognitive behavioral therapy. Scheduling the activities of a day and following the schedule help clients regain the sense of control over life. It also helps them to revive the disturbed routine. Both the clients were helped by counselor to set an effective routine and time table for studies. Focusing on studies seemed to have helped both the participants.

- Help sought from counselor: Seeking help from mental health professional has gone a long way for Jagdish. Meera has began to make some changes following her sessions with counselor, including focus on studies. Though, she needs to continue her sessions for more duration and might have to work more on changing her perceptions towards certain events. The chief therapies used in counseling were as follows:

- Person Centered Therapy: developed by Carl Rogers, this empathic, non-directive approach empowers and motivates the clients in the counseling process. One of the chief tenets of the therapy is principle of unconditional love and acceptance. The counselor has motivated Jagdish to accept and love his mother along with her illness. According to Jagdish, this formation of loving bond with the mother has not only helped her to feel better, but also became a major help in coping.

- Rational Emotive Behavior Therapy: this comprehensive, active-directive therapy focuses on identifying the irrational beliefs that are creating problems in healthy adjustment/coping and trying to replace them with more rational ones which would facilitate better emotional health and functioning.

Both the clients were helped to deal with their irrational thoughts such as 'I am the only person suffering like this, all others are happy', 'I can't deal with these frustrations all the time' or 'I am helpless in the situation, I can't do anything', etc. by quoting several real life examples, actively disputing some of the irrational beliefs and pointing out to the coping strategies that they have already been using and many more counselor could make clients re-evaluate their situations and form a realistic appreciation of it. Acceptance of the situation at cognitive level was fostered and clients were encouraged to move ahead with their life goals despite of the unfavorable situations. Once this acceptance was developed, Jagdish could effectively change his reactions to the outbursts of his mother. In turn, his mother has felt less agitated every time as her anger was met with calm and supporting reactions by Jagdish.

- Building Resilience: ultimately, resilience of the person to stress goes a long way in helping him deal with difficult life situations. As suggested by growing body of researches the reason why individuals even with most intricate circumstances can live a healthy and successful life.

The clients were helped to develop resilience to stress they were experiencing on daily basis by using several principles and techniques of above mentioned therapies.

\section{The way ahead...}

While rooting out cultural stereotypes seems difficult, making dedicated efforts towards creating awareness about mental illnesses is an attainable goal. Such attempts are need of time and increasing number of professionals need to take this up as a task.

As the support of friends, teachers and counselors seem to have played an important role, there could be small support groups formulated. They may include counselor/mentor/facilitator and people who are coping with similar situations.

The need for more comprehensive understanding of women's psychological states, contribution of genes in development of disorders and role played by environmental factors is evident. 
Considering that children of such parents are at high risk for developing some psychological problems, precipitated by both genetics and environmental factors, preventive strategies fostering mental health are necessary.

A difficult situation may oppress some; however it has the potential of motivating few others too. Many celebrities who have shared their struggles with mental illnesses exemplify the same. A Mumbai based Indian author Jerry Pinto outlines battle of his family with the mental illness of mother in his book 'Em and the Big Hoom'. Recently awarded with Windham-Campbell Prize of Yale University, the author exemplifies successful coping with psychiatric illness of parent.

\section{REFERENCES}

1. Antonovsky A. Unraveling the mystery of health: How people manage stress and stay well. Jossey-Bass; 1987.

2. Cohen S, Kessler RC, Gordon LU, editors. Measuring stress: A guide for health and social scientists. Oxford University Press on Demand; 1997.

3. Morris CG, Maisto AA. Understanding psychology. Prentice Hall; 2005.

4. Croog SH. The family as a source of stress. Social Stress 1970;1:19-53.

5. Davidson L, Roe D. Recovery from versus recovery in serious mental illness: One strategy for lessening confusion plaguing recovery. J Mental Health 2007;16(4):459-70.

6. Masten AS, Best KM, Garmezy N. Resilience and development: Contributions from the study of children who overcome adversity. Dev Psychopathol 1990;2(4):425-44.

7. Mowbray CT, Oyserman D, Bybee D, MacFarlane P, Rueda-Riedle A. Life circumstances of mothers with serious mental illnesses. Psychiatr Rehabil J 2001;25(2):114-20.

8. Oyserman D, Mowbray CT, Zemencuk JK. Resources and supports for mothers with severe mental illness. Health Soc Work 1994;19(2):132-42.

9. Oyserman D, Mowbray CT, Meares PA, Firminger KB. Parenting among mothers with a serious mental illness. Am J Orthopsychiatry 2000;70(3):296-315.

10. Nobes G, Smith M. Family structure and the physical punishment of children. J Fam Issues 2002;23(3):34973.

11. Diaz-Caneja A, Johnson S. The views and experiences of severely mentally ill mothers. Soc Psych Psychiatr Epidemiol 2004;39(6):472-82.

12. Chase SE. Narrative inquiry: Still a field in the making. The Sage handbook of qualitative research. 2011;4:421-34.

13. Patel V, Flisher AJ, Hetrick S, McGorry P. Mental health of young people: a global public-health challenge. Lancet 2007;369(9569):1302-13.

14. Saxena S, Thornicroft G, Knapp M, Whiteford H. Resources for mental health: scarcity, inequity, and inefficiency. Lancet 2007;370(9590):878-89.

$$
\begin{aligned}
& \text { Acknowledgements - Nil } \\
& \text { Conflict of Interest - Nil } \\
& \text { Funding - Nil }
\end{aligned}
$$

$* * * * * * * * * * * * * * * * * * * * * * * * * * *$ 